\title{
Analysis of School Readiness for Virtual Simulation Learning on Physics Lessons
}

\author{
Anang Purwoko ${ }^{1}$, Hermanu Joebagio ${ }^{1}$, Suharno ${ }^{1}$ \\ \{maspurkopral76@student.uns.ac.id, hermanu.joebagio@gmail.com, suharno.52@gmail.com\} \\ Universitas Sebelas Maret, Surakarta, Indonesia ${ }^{1}$
}

\begin{abstract}
This study aims to measure the level of readiness for the implementation of virtual simulations on physics learning at Muhammadiyah High School in Purworejo and find out the readiness of each factor. This research is a descriptive study using an instrument of assessment of school readiness in virtual simulation learning that includes several important factors. Factors examined in this study are infrastructure factors, teacher readiness, and student interest and acceptance. Data collection was carried out using survey methods in schools to assess school infrastructure readiness, interviews to assess teacher readiness in learning and questionnaires to assess student interest and acceptance. The results of this study indicate the infrastructure is considered ready for virtual simulation learning, the teacher's skills are considered ready to carry out virtual simulation learning and students have high interest and good acceptance. From these indicators, it can be concluded that Muhammadiyah High School in purworejo is included in the category ready to apply virtual simulation.
\end{abstract}

Keywords: Assessment, School Readiness, Simulation, Virtual, Physics

\section{Introduction}

Along with the development of Information and communications technology (ICT) science and technology, the process of learning begins to shift in the problem-based and contextual learning process. The education sector begins to develop towards technology as a source and media for learning. The use of computer and internet technology in education can increase the speed of development and educate students who are familiar with ICT. Learning at this time has penetrated into virtual learning. Technology in learning is no stranger to educators, both formal and non-formal education. Computers have become part of the implementation of learning in Indonesia. In this learning process students are required to be more active to optimize existing learning resources, especially through the Internet. In 2017 Indonesia implemented the Computer-Based National Examination. This is evidence that education in Indonesia has never been separated from technological developments.

Various kinds of instructional approaches are packaged in the form of teaching programs with computer media or CAI (Computer-Assisted Instruction) such as video tutorials, simulations, drill, and practice can be obtained through computer devices [1]. Learning using computers has been widely available and carried out in various circles. Virtual simulation is one of the development of learning media that uses computers as a learning tool. Students interact with the computer to do a simulation that has been designed in accordance with the specified scenario. Students learn as in real life, interact with the environment or objects in the computer. 
Virtual simulation is the use of $3 \mathrm{D}$ objects and the environment to create an immersive and interesting learning experience. The principle of virtual simulation is to instill, practice, and examine knowledge using interactive and environmental scenarios to reflect the situation of real conditions [2]. By using computer technology, virtual conditions can be created according to real conditions so that virtual simulations can provide an interactive learning experience. Users can freely interact with objects, test and make decisions, even users can make mistakes in the virtual world until they master the simulation. There are two main types of computer-generated virtual simulations. The first type is a desktop virtual reality environment, which can be presented on an ordinary computer screen and manipulated by a keyboard, mouse, touch screen, or joystick. The second type of virtual simulation is the total immersion virtual reality environment that is presented on multiple room-sized screens or via head-mounted stereoscopic units. Virtual computer-based simulations can create complex scenarios because they can handle a variety of scenarios. The simulation also refers to animation and various other illustrations resulting from complex scenarios [3]

The use of virtual simulation media in school learning is very necessary. The implementation of learning using virtual simulation can improve students' understanding of the concept of material, learning motivation and reduce misconceptions that occur when students learn only with printed books [4], [5]. By using virtual simulations, students can visualize a phenomenon so that it can help students observe phenomena that cannot be observed directly in class[6], [7]. Virtual simulations is a practical, limited-cost alternative to expensive physical training. Simulations also offer training where physical training cannot be conducted easily[8]. The use of virtual simulations can also reduce the risk of damage to learning by using hazardous tools and chemicals. Virtual simulations also reduce the costs needed to practice.

Learning with simulation is a technique for training and learning that can be applied to various disciplines and training participants. This is a technique to provide and strengthen experience with guidelines that evoke or replicate substantial aspects of real conditions in an interactive way. Computer-based virtual simulations can be designed to provide several key elements of cognitive understanding, such as giving theory concepts, giving assignments to students, providing guidance, providing real-time feedback, and assessing understanding of posttests and assignments [9]. Physics learning requires students to understand concepts and theories so that they can be applied in solving problems in everyday life. But not everything they learn from printed books they can observe and prove in real life. Some physics concepts require equipment that is quite expensive and complex to be proven directly in-class learning. By using virtual simulations, learning activities can visualize a phenomenon so that it can help students observe phenomena that cannot be observed directly, and relate them to phenomena that can be observed directly [10]. Virtual simulations can be done on a computer monitor using a mouse and keyboard so that it is easy to use. In this case, learning with virtual simulation can be categorized in e-learning [11].

To adopt a virtual simulation strategy and planning is needed so that the system implemented provides optimal results as expected. School readiness in facilitating learning activities with virtual simulation media is a key role in the successful implementation of learning with virtual simulations. Therefore it is necessary to assess the level of school readiness for learning with virtual simulation media. by knowing the level of readiness, the school can determine the policy or strategy to be taken later [12].

Readiness for the implementation of virtual simulations is needed to determine the condition or portrait of current organizational capabilities when compared to the expected ideal conditions. Assessment of the readiness to use virtual simulations in learning becomes important to do because often encountered obstacles such as consistency, computer literacy, limited human 
resources, infrastructure to organizational culture. Assessment of readiness can reveal the strengths and weaknesses of learning institutions in applying resources wisely [12].

Many researchers have developed an assessment of school readiness for electronic learning. In this case, virtual simulation is one part of electronic learning (e-Learning). Electronic learning readiness (ELR) model is designed to simplify the process of obtaining basic information needed in implementing virtual simulation learning. The ELR model developed by So \& Swatman [13] measures the e-learning implementation readiness based on six variables: Student's Preparedness, Teacher's Preparedness, IT infrastructure, Management Support, School Culture and Preface to meet face-to-face. Besides that, the ELR model proposed by Seakow \& Samson [14] regarding e-learning readiness in higher education in Thailand consists of five measurement dimensions, namely: Policy, Technology, Financial, Human Resources, and Infrastructure. The ELR model proposed by the Mafenya [15] states that e-learning readiness factors consist of skills, attitude, experience, organizational barrier, motivation. The ELR model proposed by Oketch [16] states that there are three factors in the readiness of e-learning, namely Technological, Culture and Contents. Hamid Mohammad Azimi [17] suggested the easing factor of the implementation of e-learning, namely ICT infrastructure, Human resources, Budget and finance, Psychological and Content. From various studies conducted, many mention technology and infrastructure as e-learning readiness factors. This is appropriate because for the implementation of e-learning it is necessary to have adequate communication and infrastructure technology devices so that infrastructure is an important component in the implementation of learning with virtual simulation media. Other researchers such as Phan [18] examine the readiness of teachers in e-learning. In addition, Eslaminejad [19] also examined the readiness of teachers in e-learning. Eslaminejad proposed an important factor for e-learning to be more effective, namely: Technical knowledge, Technical attitude, Technical skills, Technical habits as an assessment of the readiness of teachers in e-learning. Another important factor that determines the success of learning with virtual simulations is the factor of student acceptance [20]. ease of use and usefulness felt by students is a major factor in explaining the acceptance and use of new technologies. Perception of ease of use and usefulness felt by students is influenced by individual differences and by external factors such as system characteristics, availability of support, and the social context in which technology adoption is carried out [21]. Insights into the role and importance of these factors will show the difference between each student in their level of acceptance and understanding in using virtual simulations.

From the various literacies that have been described, the success of learning using virtual simulations is influenced by the school's readiness to implement virtual simulations-based learning. School readiness must be supported by several factors involved in virtual simulation learning. In this study, the factors studied were infrastructure factors, teacher readiness and student interest and acceptance [14], [15], [17], [18], [19], [20]. Infrastructure availability, teacher readiness in teaching using virtual simulations and student interest and acceptance of virtual simulations are key points of learning success with virtual simulations.

\section{Method}

This research uses descriptive analysis method. The data taken in this study are data on infrastructure readiness, teacher readiness data and student interest and acceptance data. The three factors are the most related factors to the learning process with virtual simulation. Data retrieval in this study uses three instruments. Data collection is done by survey method to assess infrastructure, interview method is used to assess teacher readiness in learning, the method of 
giving questionnaires is used to assess student interest and acceptance. This model will give results in the form of a score that can determine the school readiness rating in learning with virtual simulation. Score for the level of readiness for the application of virtual simulation media both for the average score of the question for a factor or the total average score of all questions to be considered or categorized as ready for the implementation of virtual simulations.

\subsection{Sample of Study}

A sample of this research is a single sample subject. Subjects in this research are divided into three parts. The research sub-section for infrastructure readiness factors is an assessment of the school infrastructure which includes the classroom area, computer lab area, and school environment area. The school that was the subject of the study was Muhammadiyah Purworejo High School. The research subject for teacher readiness factors was a physics teacher at Muhammadiyah High School Purworejo. Research subjects for student interest and acceptance factors were 20 students majoring in Natural Sciences who were applied physics learning.

\subsection{Tool of Study}

The instrument used in this study includes a survey instrument to assess the readiness of school infrastructure. Instrument interview guidelines are used to assess teacher readiness in using virtual simulation media. Questionnaire instruments are used to assess student interest and acceptance.

Data collection is done by survey method to assess infrastructure. Survey methods have the advantage of being able to assess variables widely. Infrastructure assessments include the availability of computer equipment, quantity of equipment, availability of the internet, projectors and IT staff in schools.

The interview method is used to assess the teacher's readiness in learning. Interviews are conducted with physics subject teachers. The interview method is used to assess more in the readiness of the teacher in learning with virtual simulation media. Assessment of teacher readiness includes teacher readiness in teaching, teacher readiness in using computers in learning, teacher activeness to use the internet as a teaching medium, teacher knowledge of elearning and virtual mediation.

The method of giving questionnaires is used to assess student interest and acceptance. The questionnaire method was chosen for assessment with many respondents. Assessment includes students' interest in virtual simulation learning and student acceptance of learning with virtual simulations. Questionnaires were given to 20 students by purposive sampling where the criteria of respondents were students of Muhamadiyah Purworejo High School majoring in Natural Sciences.

\section{Results and Discussion}

Based on the methodology and approach taken, the data is analyzed by the level of school readiness in the implementation of virtual simulations. Furthermore, the results of the questionnaire data were processed to obtain the average value of each dimension or factor of elearning readiness that was measured and the mean value of all dimensions that indicated the level of organizational readiness in implementing e-learning. Recapitulation of research data processing results can be presented in Table 1. 
Based on Table 1, the results of the score of the Virtual Readiness and Simulation Readiness Factors can be seen that the average total score is 3.53 which means that from the three factors studied it can be concluded that Muhammadiyah High School Purworejo is ready to implement virtual simulation learning. The composition of the analysis results consists of infrastructure readiness factors of 3.5 (ready), teacher readiness of 3.7 (ready) and student interest and acceptance of 3.4 (ready).

Table 1: Results of Virtual Simulation Readiness Factors and Category Scores

\begin{tabular}{lll}
\hline Factor & Score & Category \\
\hline Infrastructure Readiness & 3.5 & Ready \\
Teacher Readiness & 3.7 & Ready \\
Student Interest and Acceptance & 3.4 & Ready \\
Average total & 3.53 & Ready \\
\hline
\end{tabular}

In school readiness for the implementation of virtual simulation, media shows that Muhammadiyah Purworejo High School is ready to implement virtual simulations in learning. this is supported by the readiness of school infrastructure, the readiness of teachers to implement virtual simulation media in learning, as well as student interest and acceptance in the use of virtual simulations in learning.

The survey results on the readiness of school infrastructure for the implementation of virtual simulation media in learning get an average value of 3.5 from scale 4 . This condition is illustrated by the number of computers available in the computer lab having sufficient quantity to be used in learning according to the number of students in the class. Students have easy access to computer use at school. Lab computers can be used by students by permitting according to the system applied in the school computer lab. The school also has sufficient internet access. Muhammadiyah Purworejo High School has internet speeds of up to $10 \mathrm{Mbps}$. This speed has met for class-scale internet usage. The internet is channeled through the wifi network to all classes. This results in classes that are further located from the transmitter to get a low internet speed. Internet usage in the computer lab uses a wired network, so the computer lab has a stable and good speed. In classroom learning is supported by an LCD projector that can be used according to the teacher's needs. But not all classes have LCD projector facilities. Classes that are not equipped with a projector LCD must prepare the LCD projector before learning is done and return to the office after learning is over. This results in a lack of effective time that can be used by teachers in learning. Muhammadiyah Purworejo High School has IT expert staff as computer lab operators. Expert staff have telecommunications qualifications and have a good experience. IT experts serve as IT operators in the computer lab and facilitate teachers who need IT assistance in learning.

The results of interviews with physics teachers at Muhammadiyah Purworejo High School about the readiness of teachers to implement learning with virtual simulation media get an average value of 3.5 out of scale 4 . From these values can be categorized as teacher readiness in learning with virtual simulation media categorized as ready. This value is an illustration of the teacher's readiness. Muhammadiyah Senior High School physics teacher Purworejo Sudak has good readiness in teaching. Physics teacher Muhammadiyah Senior High School Purworejo is a graduate teacher of physics education who has teaching experience for 23 years. In teaching in the classroom, the teacher has special tricks in arranging the class so that the class can become an active environment in learning. Teachers already have syllabus and learning planning that are updated according to the curriculum applied in schools. The use of teaching materials given 
to students is standard teaching materials that are adapted to the applicable curriculum. In the learning that has been done. Teachers often use media as a tool for delivering material in learning. media that is often used by teachers in the form of physical, print and electronic media. Physics teachers always evaluate learning at the end of learning, evaluation is also done at the end of the material. The ability of teachers to use computers in learning is also quite good, as evidenced by the use of electronic learning media used in learning. Teachers are used to using computers every day. The teacher also has a personal laptop as a means of using computers to support the implementation of learning. several times the teacher had attended training on the use of electronic media to support learning in the classroom. This certainly increases the capacity of teachers in using electronic media in learning. The teacher often held consultations and discussions about the development of teaching with fellow physics teachers in Purworejo district through several forums and associations. The physics teacher at Muhammadiyah Senior High School Purworejo also often uses the internet as a teaching medium such as giving assignments to students to find material from the internet. The teacher has already applied elearning but is still in a small stage. Development needs to be done by teachers to make elearning better. Teachers have received counseling about virtual simulations and how they are applied in learning, but until this data is taken the teacher has never applied to learn with virtual simulation media.

The results of questionnaires from 20 statements given by respondents to assess student interest and acceptance showed an average value of 3.4 from a scale of 4 . Interest and acceptance of students towards learning with virtual simulations were good. From the statement given by the respondent, students have a high interest in learning using computers. Not all students know about learning using virtual simulations, $60 \%$ of them say they know with virtual simulations. $100 \%$ of students stated that they liked computer learning and new technology in learning. Students stated more understanding when learning using visual display.

\section{Conclusion}

Based on the results of the analysis carried out by Muhammadiyah Senior High School Purworejo, it was included in the category ready to carry out learning with virtual simulation. This is indicated by the average total value of $\bar{x}=3.53$. This value is greater than 3.00 so the high school is considered ready to carry out learning with virtual simulation. Although it is included in the ready category, Muhammadiyah Purworejo High School has not done learning with virtual simulation well. Some improvements in infrastructure, teachers, and students can make learning better by using virtual simulations.

\section{References}

[1] Smaldino, Lowther, and Russell, Instructional Technology and Media for Learning. Upper Saddle River, NJ: Pearson, 2008.

[2] C. Aldrich, Learning Online with Games, Simulations, and Virtual Worlds. San Fransisco, CA: Jossey Bass, 2009.

[3] Roundtree and A. Kendall, Computer Simulation, Rhetoric, and the Scientific Imagination. Lanham, MD: Lexington Books, 2013.

[4] N. Lambert and L. Watkins, "Meet Mohammed: using simulation and technology to support learning," J. Ment. Health Train. Educ. Pract., vol. 8, no. 2, pp. 66-75, Jun. 2013. 
[5] B. Kapralos, M. Hogan, A. I. Pribetic, S. M. Hope, and A. Dubrowski, "Virtual simulations and serious games in a laptop-based university: Gauging faculty and student perceptions," Interact. Technol. Smart Educ., vol. 8, no. 2, pp. 106-120, 2011.

[6] L. Dethridge and B. Quinn, "Realtime emergency communication in virtual worlds," Int. J. Disaster Resil. Built Environ., vol. 7, no. 1, pp. 26-39, Feb. 2016.

[7] V. Kumar and S. Kumari, "A Study Virtual Laboratory: Objective, Comparison and Benefits,” Int. J. Innov. Adv. Comput. Sci. IJIACS, vol. 5, no. 6, pp. 71-73, 2017.

[8] A. Dumbre, S. Manjare, P. Shinde, and C. S. Arya, "Survey Paper on Virtual Laboratory To Improve Learning," Int. J. Adv. Res. Comput. Eng. Technol. IJARCET, vol. 6, no. 10, pp. 1505-1507, 2017.

[9] D. Ramdass, "The role of cognitive apprenticeship in learning science in a virtual world," Cult. Stud. Sci. Educ., vol. 7, no. 4, pp. 985-992, 2012.

[10] N. Srisawasdi and S. Kroothkeaw, 'Supporting students' conceptual development of light refraction by simulation-based open inquiry with dual-situated learning model," $J$. Comput. Educ., vol. 1, no. 1, pp. 49-79, Mar. 2014.

[11] S. Panda and S. Mishra, "E-Learning in a Mega Open University: Faculty attitude, barriers, and motivators," Educ. Media Int., vol. 44, no. 4, pp. 323-338, Dec. 2007.

[12] Pena, M, D, Stara, V and De Rose, M., "The Failure of e-learning: Why should we use a learner centered design."

[13] P. Schubert, Ed., CollECTeR Europe 2006: Basel, Switzerland, June 9-10. Basel: Univ. of Applied Sciences Northwestern Switzerland, 2006.

[14] A. Saekow and D. Samson, "A study of e-learning readiness of Thailand's higher education comparing to the United States of America (USA)'s case," in 3rd International Conference on Computer Research and Development, Shanghai, China, 2011, pp. 287291.

[15] P. N. Mafenya, “An Investigation of First-Year Students' Pedagogical Readiness to ELearning and Assessment in Open and Distance Learning: An University of South Africa Context," Mediterr. J. Soc. Sci., vol. 4, no. 13, pp. 353-360, 2013.

[16] H. A. Oketch, J. M. Njihia, and A. N. Wausi, "E-Learning Readiness Assessment Model In Kenyas' Higher Education Institutions: A Case Study Of University Of Nairobi," Int. J. Sci. Knowl., vol. 5, no. 6, pp. 29-41, 2012.

[17] H. M. Azimi, "Readiness for Implementation of E-Learning in Colleges of Education," $J$. Nov. Appl. Sci., vol. 2, no. 12, pp. 769-775, 2013.

[18] T. T. N. Phan and L. T. T. Dang, "Teacher Readiness for Online Teaching: A Critical Review," Int. J. Open Distance E-Learn. IJODeL, vol. 3, no. 1, pp. 1-16, 2017.

[19] T. Eslaminejad, M. Masood, and N. A. Ngah, "Assessment of instructors' readiness for implementing e-learning in continuing medical education in Iran," Med. Teach., vol. 32, no. 10 , pp. e407-e412, Oct. 2010.

[20] E. M. van Raaij and J. J. L. Schepers, "The acceptance and use of a virtual learning environment in China," Comput. Educ., vol. 50, no. 3, pp. 838-852, Apr. 2008.

[21] H. Sun and P. Zhang, "The role of moderating factors in user technology acceptance," Int. J. Hum.-Comput. Stud., vol. 64, no. 2, pp. 53-78, Feb. 2006. 